\title{
SENSO E CONGEITO NO CONSTRUCTO DA DISCIPLINA PROJETUAL
}

CONCEPT AND SENSUS IN THE CONSTRUCT OF THE ARCHITECTURE DESIGN STUDIO

\section{FAVERO, MARCOS}

Arquiteto, Doutor pelo PROARQ/FAU/UFRJ. Professor do DAU/PUC-RIO.

Email:favero@puc-rio.br

\section{PASSARO, ANDRÉS}

Arquiteto, Doutor pela ETSA Barcelona/Universidad Politécnica de Catalunya. Professor da FAU/UFRI

Email: andrespassaro@fau.ufri.br

\section{RESUMO}

Este trabalho representa uma reflexão sobre as inquietudes em relação à estratégia de ensino de projeto que vem sendo praticada, desde 2003, na disciplina Projeto do Espaço do Trabalho, ministrada no terceiro período do Curso de Arquitetura e Urbanismo da PUC-Rio. A experiência de ensino apresentada aqui aborda uma metodologia para o processo projetual que abarca desde a análise perceptiva até a interpretação compositiva de índole conceitual do objeto arquitetônico.

PALAVRAS-CHAVE: ensino-aprendizagem de projeto; metodologia de projeto; análise projetual; projeto de arquitetura.

\section{ABSTRACT}

This work presents a reflection on the concerns regarding the design teaching strategy which, since 2003, has been taught in the 3rd semester's Workspace Design Studio, of the Undergraduate Program of Architecture and Urbanism at PUC-Rio. The teaching experience presented here addresses a design methodology that ranges from perceptual analysis to compositional interpretation of the architectural object's conceptual character.

KEY-WORDS: design teaching; design methodology; project analysis; architectural design. 


\section{ANÁLISE PROJETUAL COMO INSTRUMENTO DE TRABALHO}

Estamos inseridos em um processo de hibridização, no qual de forma implícita, não mais existe o valor do original e sim unicamente o valor da cópia analógica. No século da informação, da velocidade instantânea de transmissão de imagens torna-se tarefa árdua para o professor de projeto de arquitetura fazer com que os alunos apreendam os valores espaciais e formais de uma determinada obra arquitetônica.

Este quadro torna complicado estabelecer uma ponte entre o professor e o aluno para o entendimento do projeto arquitetônico como algo mais complexo do que uma simples questão imagética. Principalmente se levarmos em conta, no outro extremo, uma patética pesquisa de obras de arquitetura via internet; cujos resultados oferecem uma profusão de imagens, possivelmente produto de montagens e tratamentos, de todos os tamanhos e gostos, nas quais a relação é inversamente proporcional à publicação e ao entendimento, por conseqüência, de plantas, cortes, fachadas e detalhes. Não chegamos ao extremismo quetgliano que entende como desnecessária a visita a uma obra e que, também, quase descarta o levantamento fotográfico:

Un arquitecto debe poder conocer con total precisión cada uno de los rincones de un edificio si dispone de plantas, alzados y secciones adecuadas. Del mismo modo que a un músico le basta con leer la partitura para ser capaz de oír la música [...]. Concedo un apoyo en fotografías de época para saber como eran Oak Park, Viena o Sintras en aquel tiempo, pero nada más (QUETGLAS, 2003, p.6).

Entretanto, inserido neste dilema - como tirar da contramão o excesso e a frivolidade da informação imagética - encontra-se o trabalho de ateliê dos primeiros períodos de projeto, provavelmente na maioria das escolas de arquitetura. Associado a este dilema, percebemos outro aspecto fundamental - como evitar nas escolas de arquitetura a utilização de "pranchas de referências" simplesmente como recursos banais, esvaziadas de significados perceptivos e intelectuais (senso e conceito).

Atualmente, este problema atinge também a profissão do arquiteto, conforme indica Quetglas no artigo intitulado En Tiempos Irregulares, no qual aponta que vivemos em um tempo esvaziado de arquitetura:

El libro Casas del mundo, con mas de 2.000 fotografías a todo color, es, de largo, el más vendido en la librería del Colegio de Arquitectos de Barcelona en lo que va del año. [...] Las casas están ordenadas por tipos de emplazamiento; en el libro no se muestra ninguna planta o sección de los edificios, sino solo fotografías del exterior y del interior. El responsable de la librería me justificó el éxito. Al parecer, los arquitectos lo compran como catálogo para enseñar a sus clientes. "¿Cómo quiere la casa? ¿Le gusta el tejado de esta? ¿Y la terraza? ¿Es ésta la que le gusta? La cocina, ¿Cómo cuál? ¿Ha visto algún baño que le atraiga? ¿Como éste pero con el suelo de aquél? Bien". Hay quien compra el libro por paquetes. "Lléveselo a casa piénsenlo bien y marque las fotos que le gusten. Nos vemos este viernes." Todo eso por [...] 14,42 euros. Se lo quitan de las manos (QUETGLAS, 2001, p.8).

A banalização dos processos projetuais, mal fundamentados na cultura italiana dos anos 1970, e a fase hedonista de consumo da arte nos anos 1980-1990, ao colocar os sistemas de representação acima dos sistemas metodológicos no ensino de projeto de arquitetura (Passaro, 2003), foram desastrosas para esta prática. Ainda, podemos assistir professores "modernos", que ensinavam via método inovativo (Mafhuz, 1984, p.89), exigir de forma equivocada "pranchas de referências", revelando, muitas vezes, a falta de compreensão mais profunda dos processos projetuais estabelecidos a partir dos trabalhos de Rossi e Venturi.

Essa banalização associada ao fenômeno internet e à dificuldade de atualização das bibliotecas nas escolas de arquitetura, podem ser considerados grandes responsáveis por este excesso de informação não processada, não pensada, não discutida que "enchem os olhos" dos nossos estudantes e dos nossos clientes com uma desastrosa "imagética analfabeta".

Para nosso desespero, a maioria dos nossos alunos do ateliê de projeto, na ocasião em que elaboramos este artigo (2005), insistia em comprar livros da editora Taschen e em apenas comentar como eram bonitas ou feias algumas imagens. Será que algo mudou nos últimos anos? Ao que tudo indica, essencialmente não! Todavia, de lá para cá, é fato a difusão e, sobretudo, a acessibilidade praticamente ilimitada a internet, que no seu esteio trouxe os smartphones e tablets, fazendo desaparecer aqueles livros, que paulatinamente foram substituídos por websites, como Archidaily, Dezeen e Design Boom. Tudo isto sem evidentemente "sem poder deixar de lado" o Pinterest, rede social que é "pura imagem". 
Neste contexto, é entendido que (ainda, ou melhor, mais do que nunca) se faz necessário um aprofundamento analítico, a realização de um exercício de Análise Arquitetônica, antes da produção do projeto arquitetônico.

\section{ANÁLISE ARQUITETÔNICA}

A proposta de Análise Arquitetônica volta à ideia da arquitetura como disciplina, quase com as mesmas premissas e ferramentas inculcadas pelos italianos nos anos 1970. Voltamos a falar em processos de projetuais, nas questões do lugar, e em referências formais; definitivamente, falamos sobre linguagem e seus desdobramentos.

A partir de um conjunto de obras arquitetônicas, relacionadas pelo critério de proximidade/afinidade com o trabalho de projeto que será realizado pelo aluno na etapa seguinte, é desenvolvida esta análise arquitetônica cuja constituição pode ser percebida através de três momentos distintos, porém simultâneos, como ilustrados nas figuras 1, 2, 3 e 4:

Figuras 1 e 2 - Maquete Analítica da Casa Cantarell. (Adriana Jermann, Ana Carolina Andrade e Marcella Moura, 2005.1) *Obra original disponível em: http://www.eugeniasantacana.com/obres/Vivienda\%20unifamiliar/cantarell-pubol/pubol.html, de autoria de Eugènia Santacana + Lluís Jubert
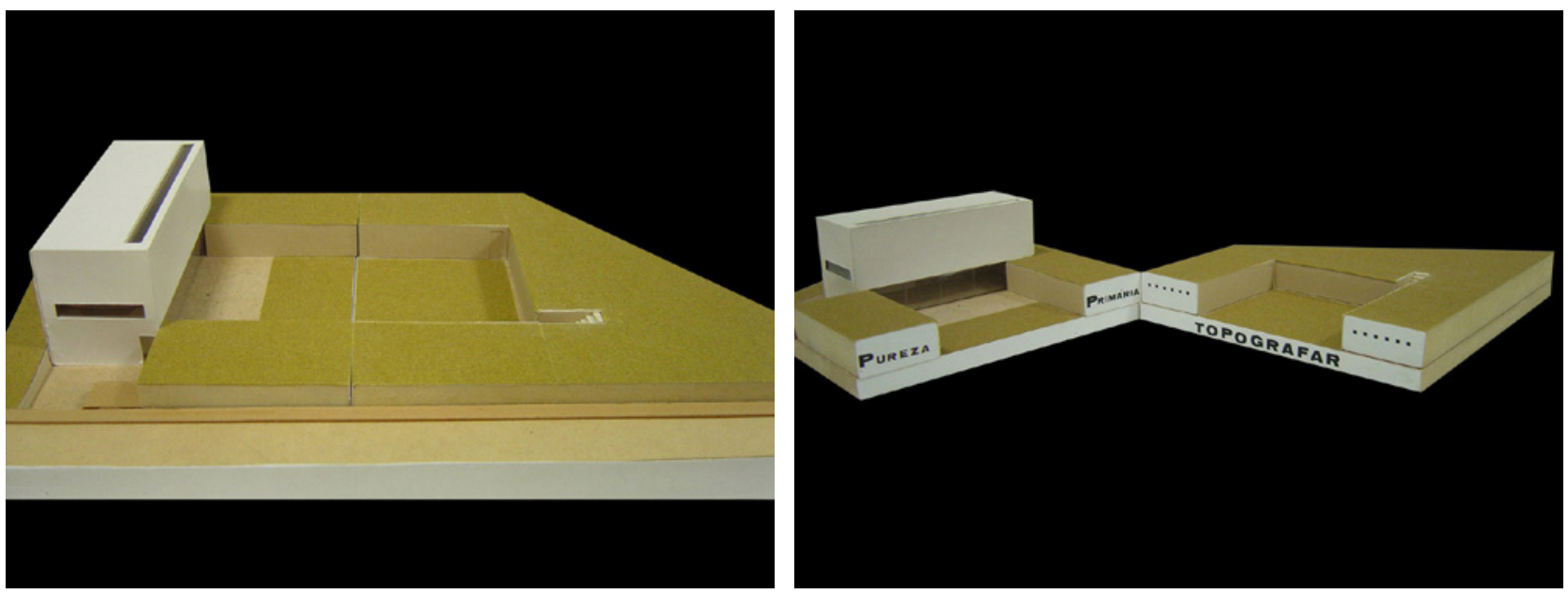

Fonte: Os autores

\section{Análise gráfica}

Desenhar e redesenhar planta, cortes, fachadas e detalhes de uma obra arquitetônica, numa escala apreensível para um aluno do terceiro período colabora para o exaustivo entendimento da arquitetura como processo histórico cumulativo. Calcar uma fotografia implica, no mínimo, em um primeiro entendimento e apreensão do espaço a partir do desenho.

Figuras 3 e 4 - Pranchas de Analise Conceitual da Casa Cantarell. (Adriana Jermann, Ana Carolina Andrade e Marcella Moura, 2005.1)


Fonte: Os autores 
Trata-se, nesta instância, fundamentalmente de um trabalho de conscientização do aluno sobre a banalidade arquitetônica da imagem pela própria imagem. Sustentar o universo da "foto" sem uma base "sensorial-conceitual" torna-se impossível, pois esta experiência passa a fazer parte da sua bagagem e do seu conhecimento histórico. Conhecer os extremos e cantos de uma obra arquitetônica é, de alguma maneira, penetrar e romper a superficialidade da imagem; e, ao mesmo tempo, entrar na questão formal e espacial. Configura-se, desta forma, um primeiro passo para romper com a ditadura da imagem.

\section{Senso e significado}

Outro propósito do exercício é superar as questões programáticas e a formulação formal e espacial. Neste momento as imagens: plantas, cortes, fachadas, detalhes e fotografias são decodificadas para encontrar possíveis abordagens perceptivas dentro do fazer arquitetônico. A partir de quatro categorias/parâmetros de concepção de projeto: morfologia, espacialidade, materialidade e implantação solicitamos ao aluno identificar palavras-chave, qualidades que de alguma maneira se relacionem intrinsecamente com aspectos sensoriais da própria obra, de forma a estimular e ampliar o campo perceptivo em relação à arquitetura. Este processo, pertinente ao campo da fenomenologia, ajuda o estudante a entender as imagens coletadas e a romper de alguma maneira com o "analfabetismo imagético". A imagem passa então a ser vivenciada, e as coisas começam a se tornar mais "palatáveis". Palavras-chave como: compactação x fragmentação, difusão x concentração, fluidez e manipulação topológica fazem o aluno romper com aquela superficialidade inicial da imagem coletada e permitem ver uma diferenciada escala de valores sobre o fato arquitetônico.

\section{Semântica e conceito}

O terceiro passo consiste em definir semanticamente, através da linguagem escrita, as palavras-chave relacionadas às categorias mencionadas. Um argumento, seja perceptivo, seja conceitual deve em princípio "sustentar" uma obra de arquitetura. Este entendimento é transformado em um "Dicionário de Conceitos Arquitetônicos"(1) , no qual se tenta esvaziar estes "conceitos" das especificidades de cada obra, ou seja, a intenção é de transforma-los em "conceitos" genéricos, abertos, operativos que, de alguma maneira, criem argumentos suficientes para a compreensão das imagens das obras. O que era superficialidade imagética passa a ser classificável e organizável de acordo com os "conceitos" elaborados.

Devemos ressaltar que existe também uma conceituação gráfico-formal que, na maioria das vezes, é inerte aos conceitos definidos através da linguagem escrita. Este outro tipo de entendimento implica num trabalho de especulação realizado a partir da análise gráfica da obra. A importância da análise gráfica associada ao processo de significação reside no entendimento mais profundo da obra analisada; superando as condições imagéticas apontadas anteriormente como desastrosas para a realização do projeto. Acreditamos que este vínculo entre senso e conceito no desenvolvimento projetual é uma das maneiras de fugir dos processos de hibridização no qual está imbuída a arquitetura contemporânea, a partir da instauração de fundamentos sólidos nos processos projetuais de arquitetura que proporciona a postura necessária para sair deste tempo esvaziado de arquitetura.

\section{PROJETO}

O "Dicionário de Conceitos Arquitetônicos" passa a ser utilizado, nesta etapa, como questão operativa conceitual. Supostamente, pode existir uma contradição neste procedimento, considerando-se que este dicionário foi constituído a partir de significados perceptivos, sensoriais. Entretanto, esta situação é diametralmente oposta na medida em que passamos a utilizar este dicionário na determinação de um argumento inicial para as categorias (morfologia, espacialidade, materialidade e implantação) numa primeira conceitualização do processo de projeto. A partir do momento em que este dicionário passa a ser utilizado em um mecanismo inverso podemos assumir o mesmo como pertinente ao campo das idéias, ou seja, efetivamente, um dicionário de conceitos arquitetônicos. 


\section{Intervenção arquitetônica}

Neste contexto, outro passo decisivo é a realização de uma intervenção conceitual referente ao primeiro exercício de projeto. Trata-se de um anexo numa das obras analisadas cuja abordagem inclui duas atitudes projetuais. Primeiro, a geração de um espaço destinado a estimular determinados "estados de ânimo" como: intimidade, ansiedade, expectativa, tranquilidade, entre outros. Tal atitude explora aspectos sensoriais pertinentes ao campo da fenomenologia. Vale ainda mencionar que a idealização deste anexo se dá a princípio através de uma descrição textual do espaço intencionado.

Figuras 5 e 6 - Maquete da intervenção arquitetônica na Casa Cantarell (Ana Carolina Andrade e Luciana Chaaya, 2005.1)


Fonte: Os autores

Segundo, o aluno confronta-se com o que denominamos mecanismo inverso. A partir de um conceito (dicionário) associado a uma das categorias/parâmetros de concepção de projeto este tem como desafio vincular a uma primeira obra arquitetônica já analisada (análise gráfica) o anexo (forma nova). Podemos traduzir este procedimento como um jogo de especulação formal ancorado num mecanismo analítico de síntese que remete ao pensamento estruturalista, podendo ser equiparável ao que a sintaxe ${ }^{(\mathbf{2})}$ é para a linguagem. Mistura-se aqui, novamente, a questão senso versus conceito.

Figuras 7 e 8 - Pranchas da intervenção arquitetônica na Casa Cantarell (Ana Carolina Andrade e Luciana Chaaya, 2005.1)
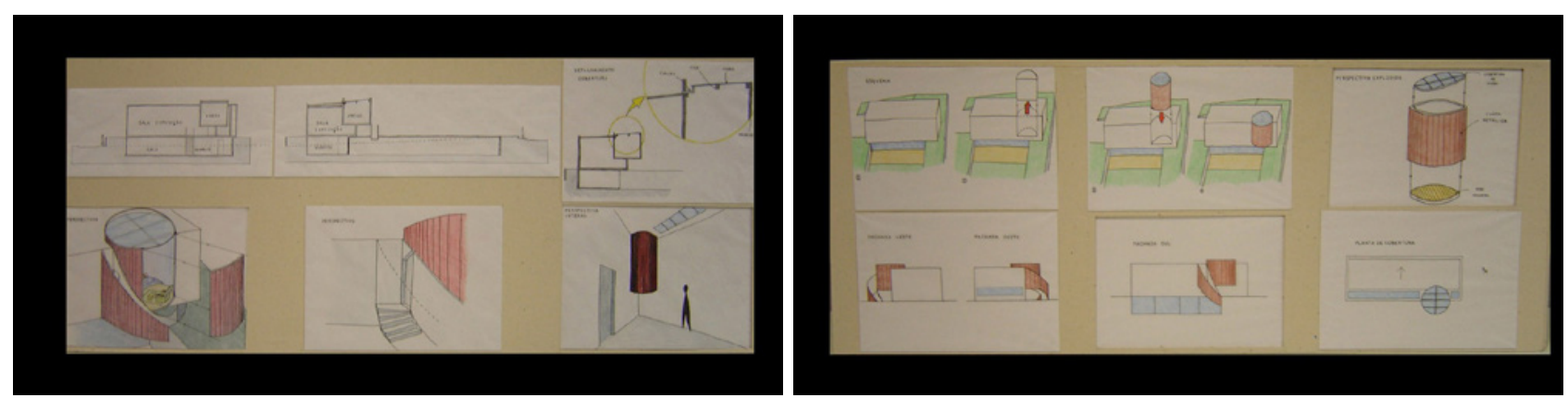

Fonte: Os autores

\section{Projeto arquitetônico}

O último exercício da disciplina, logicamente de maior "peso", consiste na elaboração de um projeto, na cidade do Rio de Janeiro, com quatro espaços tipo destinados a ateliês/moradias para artistas cujas atividades podem ser: pintura, escultura, fotografia, música, dança entre outras, associado a um espaço de uso público cujo programa deverá ser definido pelo aluno. A intenção compositiva está ancorada nos conceitos trazidos à discussão através dos exercícios de análise e intervenção arquitetônica explicitados anteriormente. No caso, é importante ressaltar que a abordagem do projeto a partir de um programa de requerimentos funcionais, é "abandonada", em favor da interpretação analítica do conceito adotado evitando assim representações estereotipadas. 
Figuras 9 a 12 - Exemplo do projeto arquitetônico desenvolvido na disciplina (Denise Kuperman, 2004.2)

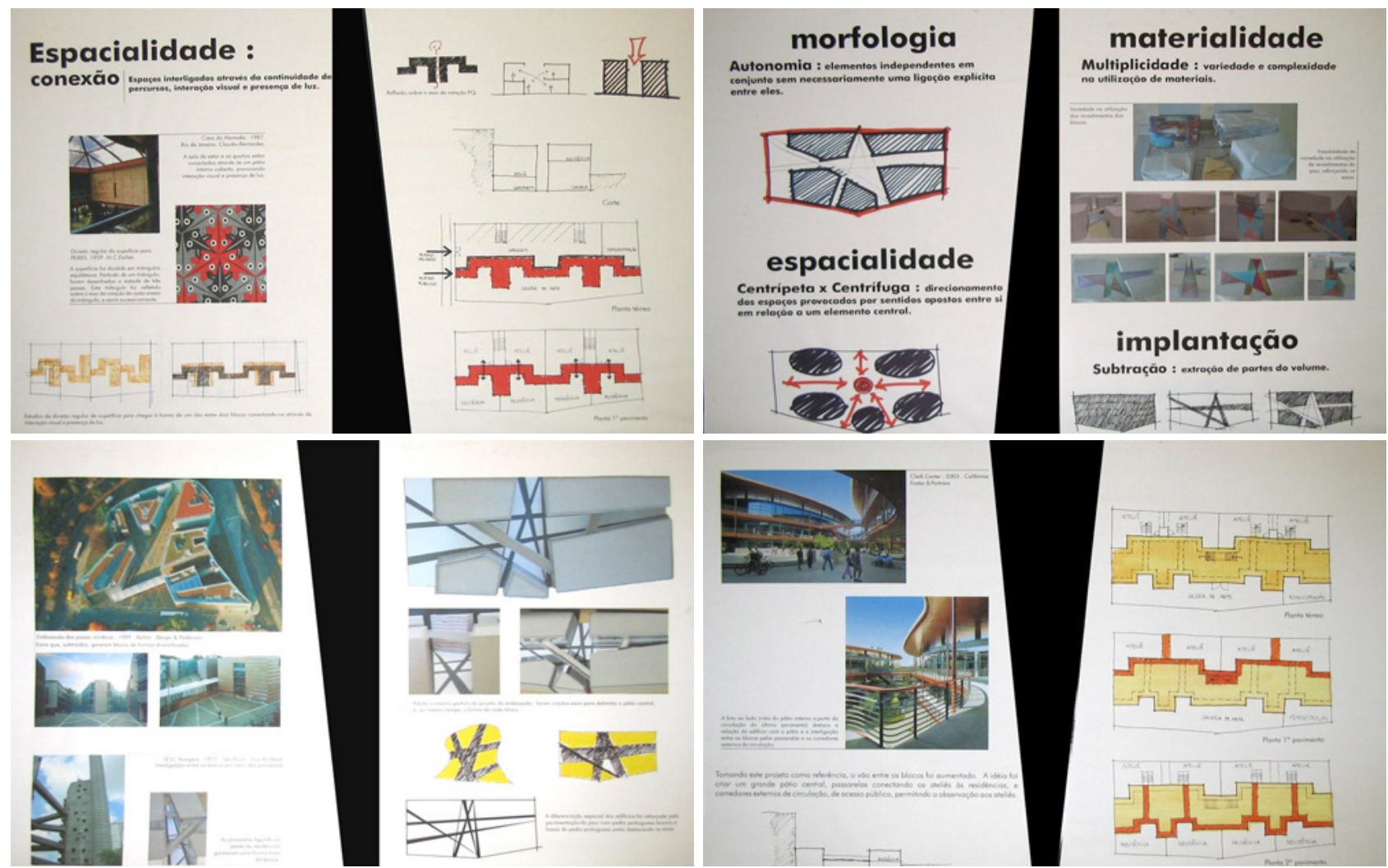

Fonte: Os autores

Figuras 13 a 16 - Maquetes e plantas do projeto arquitetônico desenvolvido na disciplina (Denise Kuperman, 2004.2)
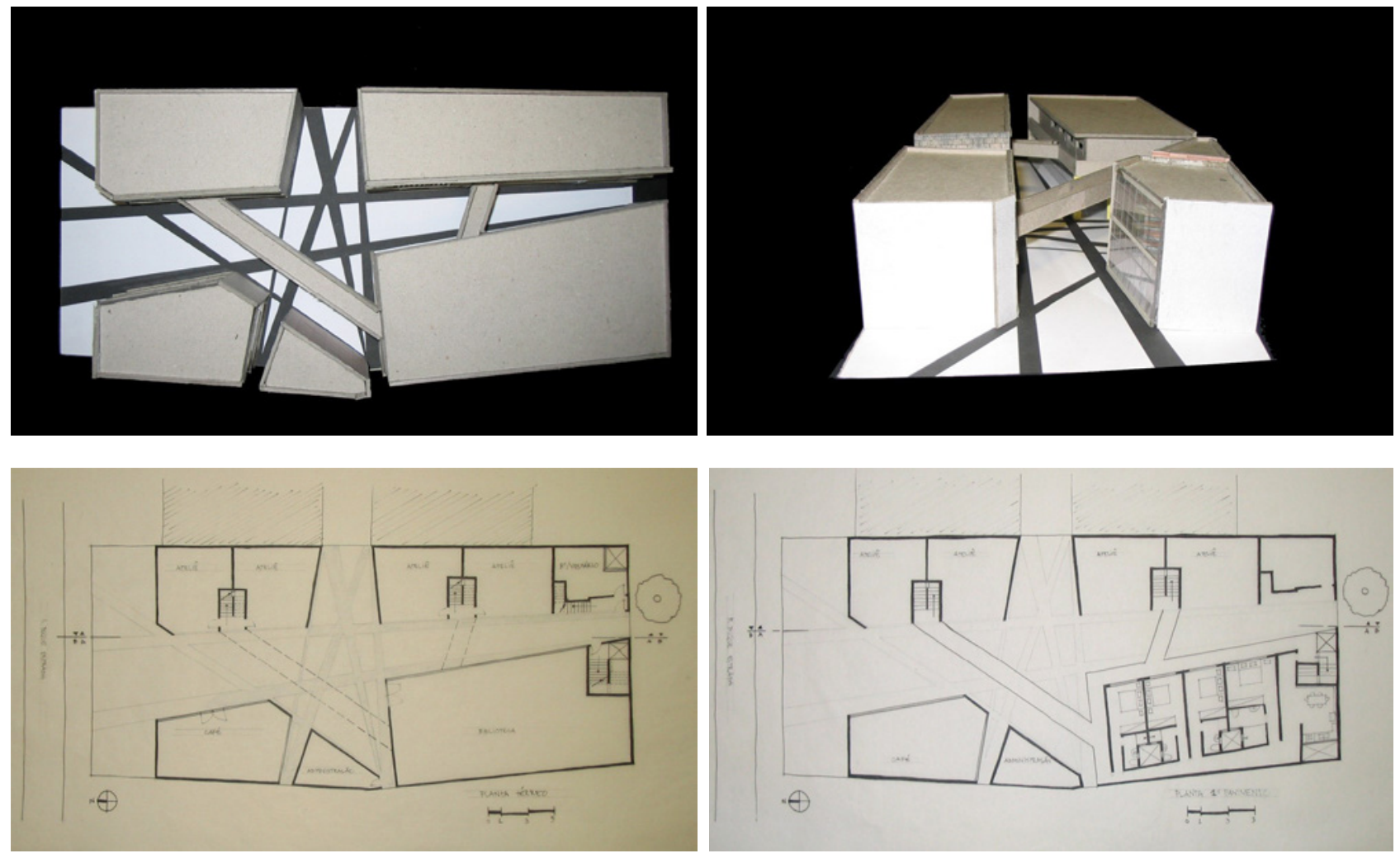

Fonte: Os autores 
Consideramos esta estratégia de ensino como um esforço no sentido de instrumentalizar o aluno para uma postura projetual crítica frente ao fazer arquitetônico. Fundamentalmente, trata-se de estabelecer uma metodologia projetual que procura ajudar o aluno a não ceder ao impulso da pura ação criativa, a não se submeter ingenuamente aos dados pragmáticos da situação de projeto e a compreender uma forma de operar em um universo de referências. Compreendemos esta estratégia, inevitavelmente inacabada, ainda como um work in progress que busca refletir sobre processos projetuais.

Para finalizar, outra citação de Quetglas, não tão radical quanto às anteriores, comentando, mais uma vez, a não validade das viagens arquitetônicas realizadas com o intuito único de tirar fotografias:

Sólo cabe una excepción a la regla: la peregrinación. El viaje por deuda y reconocimiento, por agradecimiento. De preferencia en solitario y en silencio, con el último trecho del trayecto a pie, sin nada en las manos [...] Vamos hasta el edificio para estar a su lado, sin hacer nada y sin sacar provecho alguno. Bastaría la intención de "querer conocer" mejor al edificio para invalidar nuestro gesto [...] Peregrinar es ir hasta el pabellón de Portugal en Lisboa, y colocarse bajo la sábana santa y mirar el río. Ir a Como. Ir a la avenida Junot, de Montmartre, sentarse ahí. Escuchar crujir la grava, andando hacia la capilla de los Pazzi. Ir a Ronchamp por la tarde, cuando la luz entra por los arcos del claustro, y dejarse teñir por ella. Recordar haberlo hecho. "No te mueras sin ir a Ronchamp": Oteiza lo sabía cuando se lo encomendó a Oiza, poco antes de morir - ambos (QUETGLAS, 2003, p.6).

Sem dúvida, uma escala de valores de maior consistência que as 2.000 fotos daquele livro inominável.

\section{REFERÊNCIAS}

QUETGLAS, J. Fuera de tiempo. Revista Scalae, Barcelona, n.3, p. 6-7, nov. 2003.

QUETGLAS, J. En tiempos irregulares. Revista El Croquis. Principios de siglo | En proceso (II), Madrid, n.106-107, p. 8-15, 2001.

MAFHUZ, E. C. Nada provém do nada. A produção da arquitetura vista como transformação de conhecimento. Revista Projeto, São Paulo, n. 69, p. 89-95, nov.. 1984.

PASSARO, A. Representação, determinismo sensorial e determinismo conceitual no construto do processo projetual. In: Projetar 2003, 2003, Natal, Anais... Natal: Universidade Federal do Rio Grande do Norte, 2003. 1 CD

\section{ANEXO}

\section{Dicionário de conceitos arquitetônicos ${ }^{(3)}$}

Ambiguidade. Contraditória relação entre interior e exterior gerando dúvida entre dentro e fora.

Antagonismo. 1. Posição contrária em relação ao seu meio. 2. Quebra de regras pré-estabelecidas.

Antitético. O espaço não limitado pela estrutura, este conecta-se com o exterior produzindo uma sensação de "liberdade enclausurada".

Artificialidade. Forma não encontrada na natureza com acabamento dado pelo homem.

Autístico. Necessidade de contato com o meio exterior superada pela vontade de ser independente.

Autônoma. Elementos independentes que formam um conjunto sem necessariamente existir uma ligação explícita entre os mesmos.

Compactação X Fragmentação. Oposição entre unidade visual externa e dispersão interna.

Condutividade. Intenção de fazer percorrer, física e visualmente, os espaços através de uma multiplicidade de percursos. Conexão. Espaços interligados através da continuidade de percursos, presença de luz e interação visual.

crueza. A material encontra-se em seu estado bruto, sem tratamento.

Deconstrução. Composição que, a partir de uma negação de princípios geométricos, deforma, explode, fragmenta.

Destaque. Construção sobre um plano elevado destacando o edifício do seu entorno.

Difusão x Concentração. Conceitos opostos em uma mesma obra. Difusão refere-se à dispersão. Concentração remete a noção aparente composição unitária. 
Dinamismo. Estruturas que promovem a movimentação e integração de pessoas e espaços num único ambiente.

Duplicidade. Constituição de uma obra por elementos separados sendo um destes simples e outro complexo.

Fluidez. 1.Transição dinâmica entre espaços articulados. 2. Espaços contínuos, sem barreiras ou obstruções à circulação.

3. Noção de continuidade espacial e visual, sustentada pela fusão do exterior com interior, o que permite ver e vivenciar o espaço através de um percurso livre.

Fragmentação. 1. Ato de reduzir algo em pedaços. 2. Processo de separação dos elementos de um sistema.

Horizontalidade. Forma horizontal de aspecto longilíneo devido ao seu tamanho relativo.

Ilusionismo. Sensação paradoxal de um espaço.

Interatividade. Diálogo direto entre exterior x interior onde se funde o caráter público e privado.

Leveza. 1. Característica dependente da relação entre forma x matéria transmitindo sutileza. 2. Qualidade adquirida por elementos transparentes, vazios, formas simples, cores suaves e/ou elevação do solo.

Manipulação topológica. 1. Manejar o terreno. 2. Moldar até o formato desejado.

Moldada. Configuração de uma obra o a partir dos limites da rua, da via e da quadra.

Multiplicidade. Variedade e complexidade na utilização de materiais.

Oposição. Elementos diferenciados que proporcionam um impacto visual no observador.

Osmótico. 1. Permeabilidade da luz, onde esta muda sua direção de acordo com a respectiva tonicidade. 2. De dentro para fora e de fora para dentro.

Pelicular. Forma dada por uma esquematização de módulos que compõem superfícies contínuas.

Planaridade: estruturação de um objeto através da interação entre planos horizontais e verticais que criam espaços e delimitam áreas.

Pluralidade. Identificação da variedade de elementos arquitetônicos através da diversidade de substâncias.

Simplicidade. Uniformidade de expressão através do mínimo de elementos.

Subtração. Extração de partes do volume.

Tipicidade. Intenção de uma criação cultural a partir de elementos característicos de uma região.

Totalidade. Condição de ocupar todo espaço disponível

\section{NOTAS}

(NA) Este artigo foi originalmente elaborado para o "Projetar 2005 - II Seminário sobre Ensino e Pesquisa em Projeto de Arquitetura", realizado no Rio de Janeiro, em 2005. Para esta publicação decidimos atualizar apenas o que consideramos como estritamente necessário, na medida em que, após (re)leitura atenta do trabalho - levando em consideração que estamos "falando" de um work in progress, atualmente com 14 anos -, o conteúdo deste trabalho, na forma aqui apresentada, segue caracterizando plenamente este "quinhão" de nossas "inquietudes projetuais" como professores-pesquisadores.

(1) Ver Dicionário de Conceitos Arquitetônicos em anexo.

(2) Sintaxe [Do gr. syntaxis, "ordem, disposição", pelo latim syntaxe.] S.f. 1. Parte da gramática que estuda a disposição das palavras na frase e das frases no discurso, bem como a relação lógica das frases entre si e a correta construção gramatical. In: HOLANDA, Aurélio Buarque de. Novo dicionário da língua portuguesa. Rio de Janeiro: Ed. Nova Fronteira, 1996.

(3) Fragmento relativo aos conceitos desenvolvidos pelos alunos da disciplina Projeto do Espaço do Trabalho do Curso de Arquitetura e Urbanismo da PUC-Rio durante o segundo semestre de 2004. Vale observar que, este Dicionário de Conceitos Arquitetônicos, iniciado no primeiro semestre de 2003, ao final do primeiro semestre letivo de 2005 - momento no qual este artigo foi originalmente elaborado - contava com cerca de 100 definições. O Dicionário seguiu sendo ampliado até o segundo semestre de 2007, quando deixou de ser utilizado como recurso pedagógico. Não obstante, desde então até hoje, os conceitos elaborados durante o exercício Análise Arquitetônica, a partir das categorias implantação, morfologia, espacialidade e materialidade, organizados em outro formato (fichas) são utilizados como fundamento para a definição da intenção compositiva a ser adotada no exercício Projeto.

NOTA DO EDITOR (*) O conteúdo do artigo e as imagens nele publicadas são de responsabilidade do(s) autor(es). 